\title{
Seroprevalence of Hepatitis B virus among blood donors at a tertiary care hospital in Gujarat
}

\author{
Baldev H. Patel ${ }^{1}$, Tarun P. Kotadiya ${ }^{2, *}$ \\ ${ }^{\mathbf{1}}$ Assistant Professor, ${ }^{2}$ Associate Professor, Dept. of Pathology, GMERS Medical College and Hospital, Himmatnagar, Gujarat \\ *Corresponding Author: \\ Email: kotadiyatarun71180@gmail.com
}

\begin{abstract}
Introduction: Transfusion of blood and blood components, as a specialized modality of patient management saves millions of lives worldwide each year and reduces morbidity. Transfusion-transmitted infectious (TTIs) diseases remain a major topic of interest for those involved in blood safety. Screening of TTIs among blood donors is helpful to observe the seroprevalence of HBV among healthy blood donors.

Materials and Methods: A cross-sectional study based on observance of records was conducted at Blood Bank of tertiary care hospital in Gujarat. Total 7,935 donors were screened over the period of year 2010 to 2017 according the guideline of WHO.

Results: Blood units were collected from replacement donors (54.1\%) and voluntary blood donors (45.9\%). Male donors (97.4\%) outnumbered female donors. Seroprevalence for HBV was found to be $0.98 \%$.

Conclusion: Replacement donors were higher in number than the voluntary donors. Stringent measures need to be taken on urgent basis including dissemination of information, mandatory screening protocol of blood and blood products with test having sensitivity and specificity, better donor recruitment, advocacy of voluntary donation, proper sterilization of instruments, proper disposal of contaminated material, and immunization of people at risk, particularly health care workers.
\end{abstract}

Keywords: Blood Donors, HBV, Replacement Donors, Seroprevalence, Transfusion Transmitted Infection (TTIs), Voluntary Donors.

\section{Introduction}

Blood donation is a process involving the collection, testing, preparing, and storing of blood and blood components. A voluntary blood donor is a person who donates blood voluntarily for a sense of community responsibility and does not receive payment. A replacement donor, either a friend or family member of the recipient, is someone who donates blood to replace the blood that is used for a transfusion, to ensure a consistent supply. Transfusion of blood and blood components, as a specialized modality of patient management saves millions of lives worldwide each year and reduces morbidity. ${ }^{1}$ Transfusion-transmitted infectious (TTIs) diseases remain a major topic of interest for those involved in blood safety. ${ }^{2}$

The risk of transfusion-transmitted infection with pathogenic blood-borne viruses such as hepatitis B virus (HBV), hepatitis $\mathrm{C}$ virus (HCV) and human immunodeficiency virus type 1 (HIV-1) has been reduced by improving donor selection and by the development of sensitive serological tests to screen for HBV surface antigen (HBsAg) and antibodies to $\mathrm{HCV}$ and HIV $-1 .^{3}$ However, a residual risk of viral infection persists related to the pre-seroconversion window period, infection with immunovariant viruses, immunosilent carriage, or occult carriage in the case of $\mathrm{HBV}$ infection. ${ }^{4}$

Hepatitis B virus infection is a serious global health problem affecting 2 billion people world-wide and 350 million people suffer from chronic HBV infection. ${ }^{5}$ Countries are classified on the basis of endemicity of HBV infection into high $(\geq 8 \%)$, intermediate (2 to $7 \%$ ) or low $(\leq 2 \%)$ incidence countries. ${ }^{6}$ The prevalence of chronic HBV infection in India ranges from 2 to $10 \%$. India therefore comes under the intermediate to high endemicity category. ${ }^{7} \mathrm{HBV}$ is highly infectious and can be transmitted covertly by percutaneous routes and overtly by blood transfusion. HBV infection is the leading cause of chronic hepatitis, cirrhosis, and hepatocellular carcinoma. ${ }^{8}$

Transfusion associated hepatitis B viral infection (TAHBV) continues to be a major problem in India even after adoption of mandatory screening of hepatitis $B$ surface antigen (HBsAg) by enzyme-linked immunosorbent assay (ELISA). ${ }^{1}$ The high incidence of TAHBV is reported in patients receiving multiple blood transfusions. ${ }^{1}$ Factors such as blood donations during the window period, emergence of newer transmissible pathogens, and prevalence of asymptomatic carriers pose a serious challenge to blood safety. Hence, constant monitoring and retrospective analysis of the incidence of TTIs, notably HBV among voluntary as well as replacement blood donors becomes essential to evaluate the prevalence of TTIs in the population. The present study was conducted to understand the seroprevalence of HBV among blood donors of a tertiary care hospital in Gujarat State over a period of 7 years.

\section{Materials and Methods}

This descriptive cross-sectional study was conducted at Blood Bank of GMERS Medical College and Civil Hospital, Himmatnagar, Gujarat, India. Blood bank records over a period of seven years from January 2010 to December 2017 were reviewed, retrospectively, after ethical permission of Institutional Ethical Committee. 
Records from both replacement donors as well as voluntary donors were included in the study. Precaution was taken to exclude professional donors by taking relavent history and examination.

We included seven consecutive years in our study to identify the trend of increase or decrease the incidence of TTIs. Tests are routinely done on every blood unit to exclude HBV infection. During this period 7,935 donors were tested. Blood was collected from healthy donors as criteria set by WHO. ${ }^{9}$

\section{Results}

Table 1: Gender wise distribution of donors $(\mathrm{N}=7935)$

\begin{tabular}{|c|c|c|c|c|c|}
\hline Year & Total Donors & \multicolumn{2}{|c|}{ Replacement Donors (\%) } & \multicolumn{2}{c|}{ Voluntary Donors (\%) } \\
\hline & & Male & Female & Male & Female \\
\hline 2010 & $553(7.0)$ & $336(7.9)$ & $2(5.6)$ & $207(5.9)$ & $8(4.8)$ \\
\hline 2011 & $545(6.9)$ & $326(7.7)$ & $4(11.1)$ & $208(6.0)$ & $7(4.2)$ \\
\hline 2012 & $759(9.6)$ & $380(8.9)$ & $3(8.3)$ & $362(10.4)$ & $14(8.4)$ \\
\hline 2013 & $654(8.2)$ & $242(5.7)$ & $0(0.0)$ & $384(11.0)$ & $28(16.9)$ \\
\hline 2014 & $1193(15.0)$ & $488(11.5)$ & $2(5.6)$ & $658(18.9)$ & $45(27.1)$ \\
\hline 2015 & $1048(13.2)$ & $650(15.3)$ & $4(11.1)$ & $365(10.5)$ & $29(17.5)$ \\
\hline 2016 & $1408(17.7)$ & $764(18.0)$ & $12(33.3)$ & $613(17.6)$ & $19(11.4)$ \\
\hline 2017 & $1775(22.4)$ & $1065(25.1)$ & $9(25.0)$ & $685(19.7)$ & $16(9.6)$ \\
\hline Total & $7935(100.0)$ & $4251(53.6)$ & $36(0.5)$ & $3482(43.9)$ & $166(2.1)$ \\
\hline
\end{tabular}

Table 1 and Fig. 1 shows that total 7935 blood units were collected from replacement donors (54.1\%) and voluntary blood donors $(45.9 \%)$ at the study setting during January 2010 to December 2017. Highest number (25.1\%) of blood donors noted during year 2017 and lowest $(7.9 \%)$ in 2010 . Out of total blood donors, $97.4 \%$ were male and remaining were female.

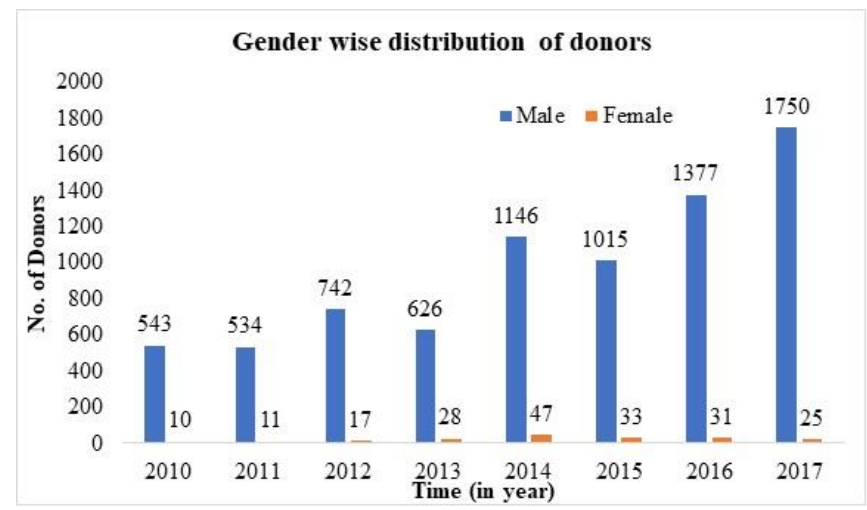

Fig. 1: Gender wise distribution of donors $(\mathrm{N}=7935)$

Table 2: Year wise distribution of $\mathrm{HBV}$ seropositive donors $(\mathrm{N}=7935)$

\begin{tabular}{|c|c|c|}
\hline Year & $\begin{array}{c}\text { Total } \\
\text { Blood } \\
\text { donors }\end{array}$ & $\begin{array}{c}\text { Total HBV } \\
\text { Seropositive } \\
(\%)\end{array}$ \\
\hline 2010 & 553 & $7(1.3)$ \\
\hline 2011 & 545 & $4(0.7)$ \\
\hline 2012 & 759 & $9(1.2)$ \\
\hline 2013 & 654 & $12(1.9)$ \\
\hline 2014 & 1193 & $12(1.0)$ \\
\hline 2015 & 1048 & $12(1.1)$ \\
\hline 2016 & 1408 & $13(0.9)$ \\
\hline
\end{tabular}




\begin{tabular}{|l|c|c|}
\hline 2017 & 1775 & $9(0.5)$ \\
\hline Total & 7935 & $78(0.98)$ \\
\hline
\end{tabular}

Table 2 shows that $0.98 \%$ blood donors were found seropositive for HBV. Highest incidence of HBV seropositive was found in year 2013.

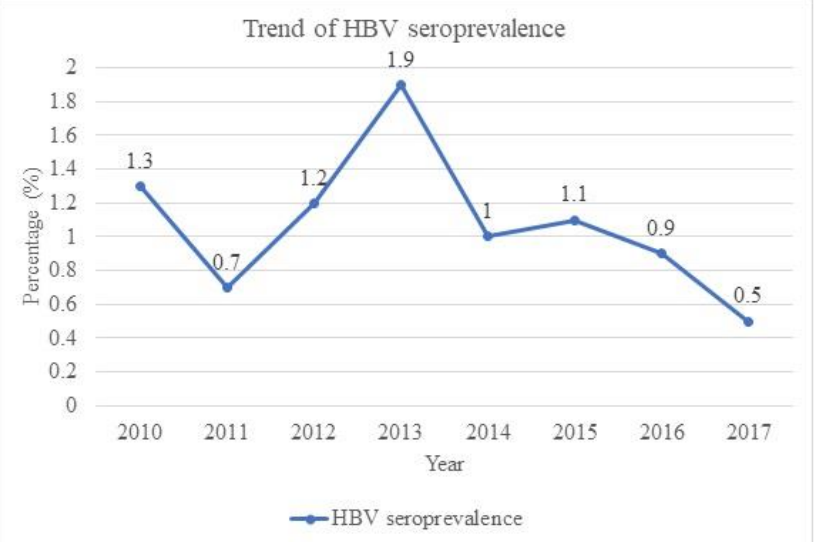

Fig. 2: Trend of seroprevalence of $\mathrm{HBV}$ among blood donors ( $\mathrm{N}=7935)$

\section{Discussion}

Blood transfusion services are an integral part of health care system, which potentially saves lots of lives every day. Blood and blood products must be free from HIV, hepatitis viruses and other threatening infections and transfused safely to the needy persons which is the basic requirement of each country of the world. According to World Health Organization (WHO) guideline, at minimum, all the blood and blood products for transfusion should be tested for HIV, Hepatitis B \& C and Syphilis. ${ }^{10}$

Replacement donation is encouraged by WHO. In present study, $45.9 \%$ were voluntary and $54.1 \%$ were replacement donors. This finding is comparable with the study from Karnataka ${ }^{11}$ and from Haryana ${ }^{12}$ which reported proportion of voluntary donors as $58 \%$ and $31.4 \%$ respectively. However, studies done by Sehgal S et $\mathrm{al}^{10}$ and Patel PA et $\mathrm{al}^{13}$ from western Ahmedabad reported voluntary blood donors as $77.6 \%$ \& $95.56 \%$ respectively.

In our study, males (97.6\%) outnumbered females $(2.4 \%)$. This finding agrees with similar other studies done in India by Shehgal $\mathrm{S}$ et al, ${ }^{10}$ Pallavi $\mathrm{P}$ et al, ${ }^{14}$ Patel PA et al,${ }^{13}$ Arora D et al,${ }^{12}$ Singh $\mathrm{K}$ et $\mathrm{al}{ }^{15}$ and Pahuja et al, ${ }^{16}$ all of which observed more than $90 \%$ of the male donors.

The World Health Organization recommends that to minimize the risk of $\mathrm{HBV}$ infection through the route of transfusion, screening should be performed using a highly sensitive and specific $\mathrm{HBsAg}$ immunoassay, that is, enzyme immunoassay or chemiluminescent immunoassay. Screening using a highly sensitive and specific HBsAg rapid assay or particle agglutination assay may be performed in laboratories with small throughput or in emergency situations. ${ }^{17}$

HBV is one of the major global public health problems. India lies in an intermediate HBV endemicity zone and the number of HBV carriers is estimated to be 50 million, forming the second largest global pool of chronic HBV infections. ${ }^{18} \mathrm{HBV}$ prevalence in general population in India is $2 \%$ to $8 \%$ and $0.5 \%$ to $3 \%$ in the blood donors, according to various studies as depicted in Table 3.

Table 3: Comparison HBV seropositive prevalence of various studies with present study

\begin{tabular}{|c|c|}
\hline Study & $\begin{array}{c}\text { HBV } \\
\text { Seropositivity (\%) }\end{array}$ \\
\hline Garg et al 2001, Rajasthan ${ }^{19}$ & 3.44 \\
\hline Gupta et al 2004, Ludhiana ${ }^{20}$ & 0.66 \\
\hline $\begin{array}{llll}\begin{array}{l}\text { Bhattacharya et al 2007, } \\
\text { Kolkata }^{21}\end{array} & \text { al } & \\
\end{array}$ & 1.46 \\
\hline Panda \& Kar 2008, Orissa ${ }^{22}$ & 1.13 \\
\hline Chandra et al 2009, Lucknow ${ }^{23}$ & 1.96 \\
\hline Arora D et al 2010, Hariyana ${ }^{12}$ & 1.7 \\
\hline Das BK et al 2011, Kolkata ${ }^{24}$ & 1.5 \\
\hline Meena et al 2011, Delhi ${ }^{25}$ & 1.43 \\
\hline Pallavi P et al 2011, Mysore ${ }^{14}$ & 1.27 \\
\hline
\end{tabular}




\begin{tabular}{|l|c|}
\hline $\begin{array}{l}\text { Kulkarni N et al 2012, } \\
\text { Karnataka }^{11}\end{array}$ & 3.2 \\
\hline Shah N et al 2013, Ahmedabad $^{26}$ & 0.97 \\
\hline Pathak S et al 2013, Delhi $^{27}$ & 0.2 \\
\hline Bodariya et al 2013, Gujarat $^{28}$ & 0.6 \\
\hline Present study & 0.98 \\
\hline
\end{tabular}

\section{Conclusion}

Present study shows that replacement donors were higher in number than the voluntary donors. Blood camps should be increased to encourage the people for voluntary blood donation, particularly in a developing country like India where availability of safe blood and blood components for transfusion is main challenge.

Considering the vast population of the country, even low prevalence amounts to large number of infected people. A prevalence of even $1 \%$ leads to millions of seropositive patients. Stringent measures need to be taken on urgent basis including dissemination of information, mandatory screening protocol of blood and blood products with test having sensitivity and specificity, better donor recruitment, proper sterilization of instruments, proper disposal of contaminated material, and immunization of people at risk, particularly health care workers.

\section{Limitation}

The present study is based on the blood bank records of past several years. As blood donors are specifically selected based on extensive questionnaire and a physical examination at a tertiary care hospital, apparently only healthy individuals with lowest risk of TTIs are allowed to donate blood. Further, the donor pool was predominantly composed of male population and with only $2.4 \%$ of female donors, the prevalence cannot be generalized to female population of this region.

Funding: No funding sources.

Conflict of interest: None declared.

\section{References}

1. Lavanya V, Viswanathan T, Malar SA, Malarvizhi A, Moorthy K. Prevalence of hepatitis B virus infection among blood donors with antibodies to hepatitis B core antigen. Int J Med Med Sci 2012;4(6):128-37.

2. Marcucci C, Madjdpour C, Spahn DR. Allogeneic blood transfusions: benefit, risks and clinical indications in countries with a low or high human development index. $\mathrm{Br}$ Med Bull 2004;70(1):15-28.

3. Abotalib AM, El-sayed HM, Amer A, El Nahla NM. Prevalence of HCV, HBV and HIV among Blood Donors in Sharkia. Egypt J Med Microbiol 2007;16(1).

4. Mollah AH, Nahar N, Siddiqui MA, Anwar KS, Hassan T and Azam MG. Common transfusion-transmitted infectious agents among thalassaemic children in Bangladesh. $J$ Health Popul Nutr 2003; 21(1):67-71.

5. Dhawan HK, Marwaha N, Sharma RR, Chawla Y, Thakral B, Saluja K et al. Anti-HBc screening in Indian blood donors: Still an unresolved issue. World J Gastroenterol 2008;14(34):5327-30.
6. World Health Organization. Prevention of hepatitis B in India: an overview. WHO Regional Office for South-East Asia; 2002.

7. Karandeep Singh, Sudha Bhat, Shamee Shastry. Trend in seroprevalence of Hepatitis B virus infection among blood donors of coastal Karnataka, India. J Infect Dev Countries 2009;3(5):376-79.

8. Surendra K, Prakash G, Bishnu RT, Manita R. HBsAg Serosurveillance among Nepalese blood donors. Ann Trop Med Public Health 2008;1(1):15-8.

9. Blood Donor Selection- Guidelines on assessing donor suitability for blood donation. Available from: http://www.who.int/bloodsafty/publications/BD selection.pdf. [Assessed on $8^{\text {th }}$ September, 2018].

10. Sehgal S, Shaiji PS, Brar PK. Seroprevalence and Trends of Transfusion Transmissible Infections in Blood Donors in Andaman and Nicobar Islands- An Institutional Retrospective Study. J Clin Diagnostic Res 2017;11(4):21-4.

11. Kulkarni N. Analysis of the seroprevalence of HIV, HBsAg, $\mathrm{HCV}$, \& Syphilitic infections detected in the pre transfusion blood: A short report. Int J Blood Transfus Immunohematol 2012;2:1-3.

12. Arora D, Arora B, Khetarpal A. Seroprevalence of HIV, $\mathrm{HBV}, \mathrm{HCV}$ and syphilis in blood donors in Southern Haryana. Indian J Pathol Microbiol 2010;53:308-9.

13. Patel PA, Patel SP, Oza HV. Seroprevalence of Transfusion Transmitted Infections (TTIs) in blood donors at Western Ahmedabad - a secondary care hospital-based study. Int $J$ Biol Med Res 2012;3:1806-10.

14. Pallavi P, Ganesh CK, Jayashree K, Manjunath GV. Seroprevalence and trends in transfusion transmitted infections among blood donors in a university hospital blood bank: a 5 year study. Indian J Hematol Blood Transfus 2011;27:1-6.

15. Singh K, Bhat $S$, Shastry $S$. Trend in seroprevalence of Hepatitis B virus infection among blood donors of coastal Karnataka, India. J Infect Dev Countries 2009;3:376-79.

16. Pahuja S, Sharma M, Baitha B, Jain M. Prevalence and trends of markers of hepatitis $C$ virus, hepatitis $B$ virus and human immunodefiiency virus in Delhi blood donors. A hospital based study. Jpn J Inf Dis 2007;60:389-91.

17. WHO Library Cataloguing-in-Publication Data. Screening donated blood for transfusion-transmissible infections: recommendations. France 2010. Available from: URL: http://www.who.int/bloodsafety/ScreeningDonatedBloodfor Transfusion.pdf

18. Datta S. An overview of molecular epidemiology of hepatitis B virus (HBV) in India. Virol J 2008;5:156.

19. Garg S, Mathur DR, Garg DK. Comparison of seropositivity of HIV, HBV, HCV and syphilis in replacement and voluntary blood donors in western India. Indian J Pathol Microbiol 2001;44:409-12.

20. Gupta N, Kumar V, Kaur A. Seroprevalence of HIV, HBV, $\mathrm{HCV}$ and syphilis in voluntary blood donors. Indian J Med Sci 2004;58:255-57.

21. Bhattacharya P, Chandra PK, Datta S, Banerjee A, Chakraborty S, Rajendran K, et al. Signi fi cant increase in $\mathrm{HBV}, \mathrm{HCV}, \mathrm{HIV}$ and syphilis infections among donors in West Bengal, Eastern India 2004-2005: Exploratory 
screening reveals high frequency of occult HBV infection. World J Gastroenterol 2007;13:3730-33.

22. Panda M, Kar K. HIV, hepatitis B and C infection status of the blood donors in a blood bank of a tertiary health care centre of Orissa. Indian J Public Health 2008;52:43-4.

23. Chandra T, Kumar A, Gupta A. Prevalence of transfusion transmitted infections in blood donors: An Indian experience. Trop Doct 2009;39:152-54.

24. Das BK, Gayen BK, Aditya S, Chakrovorty SK, Datta PK, Joseph A. Seroprevalence of Hepatitis B, Hepatitis C, and human immunode fi ciency virus among healthy voluntary fi rsttime blood donors in Kolkata. Ann Trop Med Public Health 2011;4:86-90.

25. Meena M, Jindal T, Hazarika A. Prevalence of hepatitis B virus and hepatitis $\mathrm{C}$ virus among blood donors at a tertiary care hospital in India: a five-year study. Transfusion 2011;51(1):198-202.
26. Shah N, Shah JM, Jhaveri P, Patel K, Shah CK, Shah NR. Sero-prevalence of HBV, HCV, HIV and syphilis among blood donors at a tertiary Care Teaching Hospital in Western India. GMJ 2013;68:35-9.

27. Pathak S, Chandrashekhar M. Transfusion transmittable infections - Seroprevalence among blood donors in a tertiary care hospital of Delhi. Asian J Transfus Sci 2013;7:116-8.

28. Shrivastav A, Bhavsar U, Ramanuj A, Joshi J, Agnihotri A, Bodarya O. Seronegativity HBsAg, HCV and HIV among blood donors: a five year study. Muller J Med Sci Res 2015;6(2):142-6.

How to cite this article: Patel B., Kotadiya T. Seroprevalence of Hepatitis B virus among blood donors at a tertiary care hospital in Gujarat. J Diagn Pathol Oncol 2018;3(4):335-39. 